\title{
CRÍTICA DE LA POSMODERNIDAD EN RAFAEL GUTIÉRREZ GIRARDOT*
}

\author{
CRITICS OF POSTMODERNISM \\ IN RAFAEL GUTIÉRREZ GIRARDOT
}

\author{
Damián Pachón Soto**
}

\section{Resumen}

El presente texto parte de algunas afirmaciones críticas hechas por Rafael Gutiérrez Girardot en torno al problema de la posmodernidad y, desde estas, intenta reconstruir esa crítica. En el ensayo se analiza la relación entre la Segunda Guerra Mundial, Mayo de 1968 y la llamada filosofía posmoderna. Asimismo, se expone con detalle la crítica de Gutiérrez Girardot a Michel Foucault y a algunos postulados de la posmodernidad como la crítica del intelectual y el olvido de la historia. El ensayo realiza un balance de esa crítica y, a la vez, plantea algunas perspectivas de análisis para el mundo actual.

\section{Palabras clave}

Posmodernidad, Foucault, Gutiérrez Girardot, Segunda Guerra Mundial, Mayo de 1968, humanismo, utopía.

\section{Abstract}

This text works on some statements made by Rafael Gutierrez Girardot on the issue of postmodernism and, starting from there, it tries to re-build that criticism. The essay analyzes the relationship between The Second World War, May 1968 and the so-called postmodern philosophy. It also exposes with many details the critique that Gutiérrez Girardot makes to Michel Foucault and some postulates of the postmodernism such as a critique of the intellectual and the oblivion of history. The essay shows a balance of this criticism and, in turn, raises some analytical perspectives for the current world.

\footnotetext{
* Artículo de investigación para el grupo de investigación Fray Bartolomé de Las Casas.

** Profesor Facultad de Filosofía y Letras, Universidad Santo Tomás y Departamento de Ciencias Políticas, Universidad Nacional de Colombia. Correo electrónico: damianpachon@gmail.com.
} 


\section{Keywords}

Postmodernism, Foucault, Gutiérrez Girardot, Second World War, May 1968, humanism, utopia.

A los humanistas y utopistas de hoy.

Todos los positivismos y formalismos han satisfecho dos exigencias ideológicas, al menos, de la sociedad capitalista: la afirmación de las bases injustas del progreso técnico, la acomodación y justificación de sus presupuestos económicos e ideológicos; y el sofocamiento de la crítica, el lujoso conformismo de las grandes revoluciones verbales. La América hispánica también participa de esos gozos.

Hispanoamérica: imágenes y perspectivas (1989: 70) Rafael Gutiérrez Girardot

La deconstrucción de los ídolos de la metafísica ha desvelado demasiadas cosas como para no tenerlas en cuenta.

Aprender a vivir (2007: 241)

Luc Ferry

Se puede empezar diciendo que Rafael Gutiérrez Girardot, filósofo, hispanista, germanista y crítico colombiano, fallecido en el 2005, no se ocupó de manera precisa del tema de la posmodernidad, ni tampoco hizo un estudio detallado sobre el grupo de filósofos denominados con el rótulo de "posmodernos", o una crítica de sus obras. Si bien sus alusiones al problema en distintas partes de la obra no es "detenida o detallada", sí dio pautas y sugerencias importantes que permiten reconstruir lo que podemos llamar algunos "supuestos históricos" de la posmodernidad. Reconstruir parte de esos supuestos es el objetivo de este ensayo y para esto son fundamentales algunas respuestas en entrevistas y comentarios sueltos en sus ensayos. Es de gran importancia en este proceso el epílogo al libro Nietzsche y la filología clásica (2002) y su ensayo sobre Foucault (1975). En este sentido, el presente escrito intenta explicitar esos "supuestos sugeridos" en la obra de Gutiérrez Girardot a la vez que voy "más allá" de ellos y emito algunos juicios sobre el problema -no concluidos aún- de la posmodernidad. En esto último consistirá mi aporte.

\section{-I-}

En un ensayo titulado "La vida en crisis", María Zambrano -la filósofa española a quien el crítico colombiano Rafael Gutiérrez Girardot dedicó un esclarecedor ensayo titulado "El pensamiento fragmentario de María Zambrano" (2004)-, ponía de presente cómo en los tiempos de la Segunda Guerra Mundial se perdió la confianza, las creencias entraban en crisis, se roía el fundamento de la realidad, se vivía el desamparo del hombre, su indigencia, esto es, cómo reinaba la experiencia del nihilismo, proclamado ya en el idealismo alemán por J. Paul (1797) y Hegel (1802 y 1807), y popularizado por Nietzsche en $L a$ 
Gaya ciencia, aforismo 125. Ante esta crisis y la disolución de las creencias -esas que sostienen al hombre en su mundo-Zambrano proponía "por el momento": "hacer memoria, hacer historia, recoger de las tribulaciones, la experiencia" (2005: 114).

Ahora bien, es este clima espiritual de los años cuarenta del siglo pasado el que está a la base del análisis que hace Gutiérrez Girardot de la posmodernidad y el neoliberalismo ${ }^{1}$. Tras de sí se encuentran la Primera Guerra Mundial, los fascismos de distinto modelo que la siguieron: el italiano, la experiencia estalinista, la Guerra Civil española y, como corolario, la Segunda Guerra Mundial como consumación de ese ánimo que había puesto de presente la crisis de Occidente, de su hundimiento tal como lo había hecho ya en 1918 Oswald Spengler o como se reflejaba en diversas obras de la época, entre ellas, $E l$ malestar en la cultura (1930) y Psicología de las masas y análisis del yo (1921) de Freud e, incluso, el sentimiento aparecía camuflado en Ser y tiempo (1927) de Heidegger en temas como el análisis del Man (el Uno) o el impersonal "se". De tal manera que 1945 fue el final fatal de la barbarie acumulada. Barbarie que se convirtió en una especie de certificado de defunción de los ideales modernos, de la Ilustración y de todo lo que

1 El profesor Renán Vega Cantor ha venido sosteniendo que la posmodernidad y el neoliberalismo son clones del capitalismo contemporáneo. Ha señalado que la posmodernidad habla del fin de los metarrelatos, pero a la vez ha erigido uno nuevo, eterno y único: el neoliberalismo. En este sentido, la posmodernidad es conservadora, pues promueve la permanencia y la perpetuación del capitalismo (con sus múltiples transformaciones) que la hizo posible (Vega, 1997). Hay que aclarar que gran parte de la filosofía posmoderna es crítica del capitalismo y que, incluso, ofrece alternativas o muestra posibilidades de resistencia. No toda ella es afirmativa, como podría deducirse. Esto mismo vale para la crítica de Gutiérrez Girardot que se explicita aquí. esa época había prometido: libertad, igualdad, fraternidad, tolerancia ${ }^{2}$, respeto de la dignidad humana, derechos del hombre y del ciudadano, progreso material y espiritual, democracia liberal, etc. La exacerbación de esa conciencia de crisis puesta de presente por la "era de las catástrofes" (Eric Hobsbawn) fue lo que llevó a Adorno y Horkheimer a decir en Dialéctica de la Ilustración (1947), "No es posible deshacerse del terror y conservar la civilización" (2009: 259).

Para Rafael Gutiérrez Girardot son los "suspiros filosóficos" de Karl Popper los que en estos años fundamentan los nuevos tiempos, de la posguerra, donde se quiere fundar la historia de nuevo, arrancar de cero, y donde es necesario darle la espalda a la tradición, a la historia, al pasado. Al respecto sostiene:

El actual neoliberalismo se funda en los leves, pero influyentes suspiros filosóficos de Sir Karl R. Popper, famoso políticamente por su libro La sociedad abierta y sus enemigos (1945), por una "interpretación" esquemática de Platón, Hegel y Marx, que indiferenciada y ahistóricamente, rechaza las concepciones filosóficas de intención sistemática y de explicación de los fenómenos históricos desde una perspectiva de totalidad y equipara esa intención de la tradición filosófica occidental con una praxis totalitaria [...]. Pero esa transformación correspondió al acto de remordimiento de los culpables políticos europeos -que de Platón o Hegel sabrían tanto como un lector de las Selecciones del Reader's Digest de la Segunda Guerra Mundial y del holocausto, que para borrar su responsabilidad destruyeron toda pretensión de visión total, es decir,

2 Desde Locke en el siglo XVII. 
de exigencia de la comprensión y el análisis, del "esfuerzo del concepto" (Hegel), con la seguridad de que sin ese esfuerzo no se divisaría su participación en la catástrofe (2002: 131).

La interpretación que da Gutiérrez de esta época, apunta a que después de 1945, año de la publicación del libro de Popper y también de su otro libro reconocido, La miseria del historicismo, Europa no hace una superación del pasado, no lo asume; más bien, con mala conciencia, con "arrepentimiento", intenta borrarlo, lo cual favorece la "inocencia de los políticos" implicados en ésta y también cabría decir de la sociedad misma, pues esa sociedad también era moralmente responsable, tal como después lo puso de presente Karl Jasper. Y es así como ese mundo se transforma: se desdice del humanismo, de su inutilidad, pues no pudo evitar la catástrofe y, ese vacío de tradición, por decirlo así, es llenado por el nuevo modelo técnico-científico, por la economofilia, por la adulación de la economía, nueva "teología de la sociedad moderna" (Gutiérrez, 1968: 21), esa "ciencia presuntuosa y matemáticamente aventurera" (2001: 34). Esa tecnoeconomofilia llenó el vacío que dejó el nihilismo de la Segunda Guerra Mundial, a saber, la falta de tradición ${ }^{3}$. Precisamente, no sobra recordar que es esta fecha la que es considerada por algunos teóricos como la del nacimiento de la posmodernidad, época que Lyotard, quien puso de moda el término, calificó precisamente de "relajamiento" (1994).

3 Michel Foucault se ocupó del nacimiento del neoliberalismo (ordoliberalismo) en Alemania y en Estados Unidos. Para ello, partió de los años treinta cobijando la época a la que alude Gutiérrez. El filósofo colombiano no conoció esos textos de Foucault que hoy se encuentran en el libro Nacimiento de la biopolítica (Foucault, 2008).
Ahora bien, esto que llamó el segundo desencanto del mundo -el primero fue ante la Edad Media; el segundo ante los principios de la misma modernidad- se tradujo en un "relajamiento" del pensar, pues lo que sucedió posteriormente fue "la burocratización del saber", burocratización que implicó un "estrangulamiento de la percepción y afirmación de la realidad contradictoria, es decir, del conocimiento desprevenido del mundo" (Gutiérrez, 2002: 130), esto es, una actitud acrítica frente a los procesos globales, contextuales y una toma de partida por lo inmediato. En este estrangulamiento las ciencias humanas sufrieron el mayor golpe, pues se les empezó a dejar de lado. Estas ciencias empezaron a ser tildadas de anacrónicas. En reemplazo, el llamado progreso científico empezó una carrera hipodrómica-mente irracional, pues equiparó "el movimiento de las ciencias a una carrera de caballos, esto es, la de competencia" (2002: 143).

Gutiérrez Girardot no profundizó más en lo que sucedió después de 1945, pero sus apuntes y su análisis, apenas indicados, se pueden comprobar fácilmente con la historiografía social moderna. Hasta el momento se tienen varias afirmaciones importantes: después de 1945 emerge el neoliberalismo, éste corresponde a una ideología que quiere olvidar el pasado e iniciar un nuevo tiempo. Así se funda lo que Gilles Lipovetsky llamó: "la era del vacío" (2002). De paso, ese nuevo tiempo, ese adanismo, implica un olvido de la tradición, desencanto del humanismo, tecnificación del saber y burocratización de la universidad. Pero hay otra consecuencia importante que se relaciona directamente con ese nuevo modelo de sociedad: es el canto a lo efímero, a la rapidez, a lo inmediato, características que hoy están a la base de la actual sociedad capitalista, de la llamada posmodernidad. Esta consecuencia la encontró Gutiérrez en el mismo Popper. En efecto, en La miseria del historicismo Popper la emprende contra 
las filosofías de la historia; y en La sociedad abierta y sus enemigos sostiene:

La historia de la humanidad no existe; sólo existe un número indefinido de historias de toda suerte de aspectos de la vida humana. Y uno de ellos es la historia del poder político, la cual ha sido elevada a la categoría de historia universal (Popper, 1967, t. II: 385).

No es necesario forzar la interpretación de Gutiérrez para sostener que afirmaciones como estas le quitan responsabilidad al poder político en las catástrofes del siglo XX. Por lo demás, Popper alude a la dispersión histórica y sostiene: "la historia no tiene significado" (1967: 384). Popper en realidad no dice muchas cosas novedosas pues parte de estas premisas; por ejemplo el rechazo a las filosofías de la historia, ya lo había hecho Nietzsche en el siglo XIX. Pero no se puede olvidar su notoria influencia en la sociedad de la posguerra.

Fueron las "soluciones" de Popper las que ayudaron a despachar las filosofías sistemáticas, como las de Platón, Hegel y Marx, y su "política de ingeniería social gradual" apuntaló el inmediatismo. Al respecto, frente a las pretensiones sistemáticas, a las visiones de totalidad; frente a las revoluciones y los proyectos macro de transformación social:

Popper propuso, en cambio, una política de pasos breves, de soluciones inmediatas a problemas inmediatos, sin percatarse de que esa inmediatez reduce considerablemente la posibilidad de captar adecuadamente el contexto precisamente de esa inmediatez, y que la renuncia al contexto convertía a la vida política y social en una convivencia de conformistas, de autómatas consumidores... (Gutiérrez, 2002: 131).

Al olvidar el pasado y proponer una "política de pasos breves", de inmediatismo; al rechazar la visión total de la escena, las pretensiones sistemáticas de explicar los fenómenos y situarlos en contextos mayores que los hacen posibles; en últimas, al renunciar al "esfuerzo del concepto" que permite establecer los nexos entre los fenómenos, sus relaciones, se cae en un pensamiento afirmativo de lo existente; no hay posibilidad de una comprensión global que permita unir el presente de la posguerra con el pasado que la engendró. Así, se desemboca en el inmediatismo, y al no poder explicar nada de los fenómenos, se promueve el conformismo y el automatismo frente a la nueva sociedad, al "relajamiento" que no es otra cosa que aceptación de lo que es, tal y como es. Es decir, lo que María Zambrano llamó, en La agonía de Europa (1945), la pérdida de los ideales y la sumisión ante la "pavorosidad de los hechos", "la ciega servidumbre a la realidad" (Zambrano, 2000: 25-26) o la fati-latría. De tal manera que para Gutiérrez no se trataba de olvidar el pasado, sino de asumirlo, superarlo conservando en términos de Hegel, de "hacer memoria", "recoger de las tribulaciones, la experiencia", como decía Zambrano en la época.

¿Qué podemos decir de la interpretación que da Gutiérrez y que he ampliado y contextualizado arriba? En primer lugar, es cierto que a partir de 1945 el mundo comienza una transformación sin precedentes. De ahí que muchos sitúen la posmodernidad a partir de esa fecha o a partir de 1950. Otros, a partir de Mayo del 68. Y esas transformaciones son, inicialmente, económicas. En efecto en 1944, en Breton Woods se crea la actual organización económica mundial: nace el Banco Mundial-BM, el Fondo Monetario Internacional -FMI, y lo que sería la actual Organización Mundial del Comercio-OMC. Nacieron en 
Estados Unidos para regular la economía y financiar la reconstrucción de Europa. Desde ese momento EE.UU. se convirtió en la potencia económica mundial, crecimiento que sólo le disputó, por lo menos hasta los años sesenta, la Unión Soviética. Ese período que va entre 1945 y 1973 es lo que se conoce como los "años dorados". Durante este tiempo, Europa crece económicamente, en especial Alemania en la era de Konrad Adenauer y el conocido “milagro alemán” (1949-1963), lo mismo sucede en Francia. En este período se formó una verdadera economía global, la industria eliminó gran parte del campesinado, crecieron las ciudades (ese mismo proceso se dio en América Latina entre 1930 y 1970, según José Luis Romero), tomaron auge las profesiones técnicas y especializadas para responder a las nuevas exigencias del mercado, creció la enseñanza superior, aumentó la alfabetización, ingresó la mujer al mercado laboral (Hobsbawn, 2006: 313). Por este motivo varios autores hablaron en la época de "la aldea global" (Marshall McLuhan), "la sociedad opulenta" (Kenneth Galbraith), la "sociedad industrial avanzada" (Marcuse) y otras expresiones aún más proféticas y que hoy son una realidad innegable: "la sociedad del espectáculo" (Guy Debord). Todas estas expresiones denotaban los cambios producidos y aludían a la nueva realidad.

En segundo lugar, hay que aclarar que esta época si bien presenta transformaciones económicas, no es precisamente el inicio del neoliberalismo, pero si su antecedente. En este período se da el auge de la socialdemocracia (ese anfibio entre capitalismo y socialismo), del Estado intervencionista, de la "planificación económica" o la tecnocracia de la economía, que contienen características no compatibles del todo con el actual sistema neoliberal. El neoliberalismo surge, en estricto orden, a partir de 1973 con la crisis del petróleo y del patrón de conversión dólar-oro, que valga decir de paso, benefició siempre a Estados Unidos. Ahora, la crisis del 73 es sólo la consumación de la iniciada pocos años antes. En Europa decae el empleo, disminuyen los salarios o no cumplen las expectativas para el consumo, desmejora la vida de la clase trabajadora que cada día era más absorbida por el sistema capitalista, eliminando de esta manera la oposición política, etc. Aquí los treinta años dorados del capitalismo entraban de nuevo en crisis. Es a partir de 1973 cuando emerge con fuerza el neoliberalismo, el cual tuvo sus impulsos en Inglaterra con Margaret Tatcher, en EE.UU. con Ronald Reagan y en América Latina a partir del Consenso de Washington formulado por Jhon Williamson en 1989.

Hay un tercer elemento que es importante señalar para este período. En Historia del siglo $X X$, se sostiene: "La edad de oro perdió su brillo. No obstante había empezado y, de hecho, había llevado a cabo en gran medida, la revolución más drástica, rápida y profunda en los asuntos humanos de la que se tenga constancia histórica" (Hobsbawn 2006: 289). Y ¿en qué consistía esa revolución? El asunto es bien sabido: a todas las transformaciones económicas, políticas, sociales y culturales. El mundo cambió para siempre. Es la época de la revolución social y cultural de los años sesenta: la aparición de la juventud en el escenario social, la cual creó un imaginario que hoy se manifiesta por doquier: la loa a la belleza, el miedo a la vejez. Desde ese entonces "la juventud pasó a verse no como un paso para la vida adulta, sino, en cierto sentido, como la fase culminante del pleno desarrollo humano...la vida iba claramente cuesta abajo a partir de los 30 años" (2006: 327). Desde luego, lo joven es lo nuevo, lo que surge y estremece. A la par la juventud tiene su irrupción en el espacio social, exterioriza conductas consideradas inaceptables en público, crea un nuevo mercado de la moda, de los viajes, vive ávida de experiencias. A esto se le suma la revolución sexual, 
su liberalización, la minifalda, la droga, el rock. En pocas palabras, el quiebre y la erosión de los viejos valores, de las tradiciones. De ahí el cuestionamiento a la familia, a la autoridad de los padres, la escuela y su pedagogía; la disminución del matrimonio, el aumento de las uniones libres, aumento de los divorcios, de los hijos "ilegítimos"; auge de las comunas, las congregaciones hippie. Igualmente, el surgimiento del feminismo, el antirracismo en Estados Unidos, el ambientalismo, la reivindicación de los derechos de los homosexuales y el fin de los imperialismos en África y Asia, la descolonización del mal llamado Tercer Mundo. Esto le permite decir a Hobsbawn: "la liberación personal y la liberación social iban, pues, de la mano, y las formas más evidentes de romper las ataduras del poder, las leyes y las normas del estado, de los padres y de los vecinos, eran el sexo y las drogas" (2006: 334).

Todos estos fenómenos tomaron cuerpo en Mayo del 68, año en el que según Antonio Negri terminó el siglo XX (2007: 23). Ese suceso que influyó profundamente en Europa y sobre este significado la academia no se ha puesto aún de acuerdo, por ejemplo, entre quienes lo consideran una revolución y quienes no; o de quienes piensan que fue sólo un movimiento esporádico, contra la autoridad de la familia, el Estado y el consumismo y otros valores de la sociedad capitalista vigente. Aquí sólo basta citar la defensa que hace, por ejemplo, Jean-Luc Nancy, al poner de presente cómo es un movimiento que expresa su descontento, cómo en éste confluyeron los estudiantes, los ferroviarios, los obreros (no el partido comunista) y los intelectuales. Mayo del 68 mostró un nuevo ethos: no se hace la revolución con grandes cuerpos doctrinarios, ni concepciones o ideologías, era un abandono de la "era de la historia", fue un ethos con desconfianza de la representación de los partidos que tendía a "desvincular la acción política del marco convenido para el ejercicio o la toma del poder" (Nancy, 2009: 24; 61 y ss). Es decir, Mayo del 68, con su espontaneidad, derribó muchas viejas doctrinas, viejas nociones y viejos ídolos. Sin embargo, para autores como Hobsbawn ese movimiento tuvo más significación cultural que otra cosa, no política ${ }^{4}$.

Por otro lado, autores como Luc Ferry y Alain Renaut se han constituido en duros críticos de ese movimiento, pero sobre todo, para lo que interesa aquí, cabe resaltar lo que ellos evidencian en su famoso y polémico libro El pensamiento del 68. Ensayo sobre el antihumanismo contemporáneo (1985) y otras obras, donde relacionan todos estos hechos con la publicación de los libros de autores como Foucault, Deleuze y Derrida (Tobar, 2004: 170-171). En pocas palabras, los grandes motivos de estas obras, tales como la crítica de la razón, la crítica de la verdad, su abandono o rechazo, así como la "actitud de sospecha" o "voluntad de deconstrucción" que llevó al cuestionamiento de todos los discursos filosóficos, las teorías, las ciencias humanas, de donde surgió la moda de hacer genealogía, archivística, arqueología, etc., se corresponden con el fenómeno cultural de Mayo del 68, es decir, para situarnos en lo que venimos tratando, de la revolución cultural y social producidos después de 1945 en los 30 años dorados del capitalismo de la posguerra.

4 En nuestro medio, por ejemplo, el profesor Carlos Antonio Aguirre ha mostrado que Mayo del 68 cuestionó los tres pilares fundamentales de la producción y la reproducción de la cultura de la vieja sociedad anterior al 68: la familia, la escuela y los medios de comunicación. Enfatiza la manera cómo esa revolución, que debe vincularse a la Revolución China, la Primavera de Praga, México en 1968, etc., transformó la historia, en especial, la noción de totalidad social, y produjo una verdadera eclosión de formas, enfoques, intereses, temas de investigación, fomentó la interdisciplinariedad, etc., lo cual representaba justamente esa nueva forma de ver la realidad social (2010: cap. IV). 
De tal manera que los finales de los años sesenta es una época de "la impugnación del saber", contra la "certeza de lo verdadero" y una "lucha contra todas las opresiones localizadas" (Vermeren, 1995: 89) en relación con su pasado inmediato.

Alex Callinicos, por su parte, ha expuesto en su libro Contra el postmodernismo. Una crítica marxista, que el auge del discurso posmoderno se debe a los sueños fallidos de la utopía del 68 (también para Agnes Heller quien sitúa el posmodernismo a partir de ese año), al desencanto de ciertos intelectuales que se habían comprometido con los movimientos (como Lyotard y su "peregrinación" por el grupo "Socialismo o barbarie", D. P.), a la desbandada de la izquierda y al crecimiento de la clase media que se acomodó al consumismo de la nueva era del capitalismo. Esa clase media promocionó la ampliación de un modelo de vida que parecía al alcance de todos, ilustrando esa nueva vida con el individualismo, el hedonismo, la apatía política. De esta manera se dio la ilusión de una libertad sin límites, pero como ya habían mostrado Adorno y Marcuse, se trataba sólo de una "libertad organizada", de "una falsa libertad" que producía una "conciencia feliz", tal como Marcuse lo había comprobado con antelación en 1964 en su libro El hombre unidimensional (1981: 114). Resumiendo dice Callinicos: "Esta coyuntura, -la prosperidad de la nueva clase media, combinada con la desilusión política de muchos de sus más destacados integrantes-suministra el contexto de la proliferación de los discursos sobre el postmodernismo"5 (1998: 317). Pero con la

$5 \quad$ Hay que decir, además, que con la caída del Muro de Berlín el discurso posmoderno se fortalece. Eso fue lo que llevó, de manera entusiasta, a Francis Fukuyama a plantear el fin de la historia y el triunfo definitivo de la democracia liberal y el capitalismo, con lo cual se producía el "reconocimiento" universal gracias al mercado y así se acabarían las guerras estabilización de la sociedad capitalista, sólo se llegó a que la “oposición se reduce entonces al consumo de las obras de arte posmodernas, cuyos autores buscan encarnar en ellas este tipo de pensamiento" (1998: 320); asimismo, "escuchar, en un estilo adornado con la aparente profundidad y autentica oscuridad de la retórica" que no se puede cambiar el mundo" (1998: 320). De este modo la posmodernidad se vuelve afirmativa, alimenta el conformismo y el automatismo tal como Gutiérrez lo expuso al referirse a los "suspiros filosóficos" y políticos de Popper.

Es en este contexto donde se inscriben los comentarios de Gutiérrez Girardot sobre la posmodernidad y la relación de ésta con el neoliberalismo de la posguerra. Por lo demás, Gutiérrez calificó a Mayo del 68 como un movimiento complejo y confuso, sosteniendo, como Luc Ferry y Renaut, por ejemplo, que la filosofía de Foucault estaba relacionada con ese movimiento.

\section{-II-}

\section{La posmodernidad, Nietzsche $y$ Foucault}

La poesía de Nietzsche es, como su pensamiento, una danza en hielo resbaloso, que por eso no sólo se mueve entre los giros de la contradicción sino se sustrae a toda captación lógica y a toda comprensión unificadora.

Rafael Gutiérrez Girardot (2002: 154)

mismas (Fukuyama, 1992). Es decir, Fukuyama mostraba que la historia, con la derrota del comunismo, daba la razón a lo plantado como muerte de los metarrelatos, las utopías y las ideologías. Desde ese momento, no parecía posible otro mundo distinto al capitalista. Este sentimiento se ha naturalizado hoy en la gente $\mathrm{y}$ en los gobiernos del mundo. 
En su libro Heterodoxias (2004) al referirse a Antonio Machado sostiene Gutiérrez Girardot que el poeta "no cabe en esa impaciencia histórica y pretenciosamente norteamericana que engendraron algunos arquitectos del Imperio y que expresa la palabra postmodernidad" (2004: 206). Es claro que aquí se refiere al arquitecto norteamericano Robert Venturi y al inglés James Sterling “quienes por primera vez introdujeron el término postmoderno en su uso popular" (Callinicos, 1998: 21). La posmodernidad es un término tomado de los Estados Unidos, de la arquitectura, y fue de allí precisamente desde donde se amplió a las otras áreas del saber y del mundo social, adquiriendo popularidad con La condición posmoderna de Lyotard en 1979. Por lo demás, la alusión a la "impaciencia histórica" que hace Gutiérrez se debe a esa no asunción del pasado después de 1945, por eso la posmodernidad es "una venganza del pasado no asimilado", a lo cual se debe, según él, también el éxito de la filosofía de Habermas en Alemania.

En una entrevista, y frente a la pregunta ¿cuál es la tarea del intelectual en medio de las llamadas corrientes de la posmodernidad?, el filósofo colombiano respondió:

Yo creo que la llamada posmodernidad es una especie de acompañante del neoliberalismo. El neoliberalismo es una falsa libertad, una falsa oferta de varias posibilidades. Los posmodernismos son un acompañante ideológico de un anacronismo que considera no necesitar la inteligencia. Incluso para los filósofos posmodernos más radicales los intelectuales no existen, no tienen sentido. Si una tarea del intelectual es la crítica y ya todo es válido por sólo existir ¿entonces para qué intelectuales? La posmodernidad ha suprimido el pensamiento. Esto hace más fuerte la necesidad del intelectual: su honradez, su sinceridad su sentido del rigor el desafió de no dejarse seducir por ninguna de estas modas y cuestionarlas (Gutiérrez, 2009: 8).

En esta respuesta hay varios puntos que ya podemos comprender fácilmente: la relación de la posmodernidad con el neoliberalismo ("reproducción del darwinismo más absurdo") y la alusión a la "falsa oferta de varias posibilidades", esto es, a la "libertad organizada" mencionada arriba que lleva a la adaptación a la sociedad, al conformismo y al automatismo. Pero, ¿a qué se refiere el crítico colombiano cuando alude a que la posmodernidad considera "no necesitar la inteligencia"? La respuesta la da el propio Gutiérrez: a la crítica al intelectual que hicieron los filósofos franceses: no se trataba de ser un Sartre tratando de recuperar el sujeto de la praxis, sino que, entre otras cosas, el sujeto ya no era centro de actos, y el intelectual no debía asumir una posición especial para pretender ilustrar a las masas, ni mucho menos para representarlas y pretender ser la conciencia de las mismas. La crítica la realizó Foucault hasta la saciedad: "Los intelectuales han descubierto, después de las recientes luchas que las masas no los necesitan para saber: ellas saben perfectamente, claramente, mucho mejor que ellos; $y$ además lo dicen muy bien" (Foucault, 2008: $25)^{6}$. Pues bien, la respuesta de Foucault no sólo muestra un cambio en la perspectiva de

6 Foucault decía que el intelectual no debía modelar la conciencia de las masas, pero sí ayudar a formar voluntad política, así como luchar desde adentro contra el poder. Sin embargo, hay que aceptar que hay cosas que el intelectual sabe y que las masas no, por ejemplo, asuntos técnicos y complejos sobre la economía, la legislación, las relaciones internacionales, etc., esto es, aspectos que pueden estar directamente relacionados con la situación de opresión de las masas y sobre los cuáles estas no están en capacidad de dilucidar por sí mismas. Sólo saben lo que les pasa en formas muy concretas y visibles de poder que las afecta. 
la praxis política (muestra también la forma como se alinea con su amigo Deleuze, con quien mantuvo una complicidad de elogios mutuos), sino que pone de presente que los viejos esquemas donde un partido dirige la revolución representando a las masas obreras ya no es posible, es decir, hay una alusión al fracaso del marxismo. En ese sentido, ese rechazo a los intelectuales se puede interpretar como parte de ese desencanto frente a la revolución y su práctica política.

Por otro lado, si no se "necesita la inteligencia" el hecho se debe a las nuevas dinámicas que ha tomado la sociedad "pomposamente trivial”, esto es, a lo que Agnes Heller llamó el "todo vale".

El todo vale puede interpretarse de la siguiente forma: tú puedes rebelarte contra lo que te apetezca, pero déjame a mí rebelarme contra algo en particular contra lo que quiero rebelarme. Y también está la alternativa: Permíteme que no me rebele contra nada porque me siento totalmente a gusto (Heller, 1994: 130).

Es decir, todo da igual, es indiferente. Aquí se sintetiza lo que Gutiérrez sostiene: "todo es válido por sólo existir”. Y si esto es así, quiere decir que todo está legitimado. Y si todo es aceptado con sus derechos, no puede existir criterio alguno para delimitar, separar y juzgar nada. En pocas palabras, el intelectual no tiene nada que decir, ni nada que discriminar o lo que es lo mismo, la posmodernidad ha abolido la crítica y la reflexión. Y dentro de esas posibilidades está aceptar el mundo tal como es, sin esperanza de cambiarlo pues también se tiene el derecho de no rebelarse contra "nada porque me siento totalmente a gusto".

Alex Callinicos ha sostenido que Derrida, Foucault y Deleuze "enfatizaron el carácter fragmentario, heterogéneo y plural de la realidad, negaron al pensamiento humano la capacidad de alcanzar una explicación objetiva de esa realidad y redujeron al portador de ese pensamiento, el sujeto, a un incoherente revoltijo de impulsos..." (1998, p. 22). Pues bien, esa renuncia a la pretensión de totalidad y de objetividad y la acentuación de lo efímero, lo ligero, los hechos, lo fragmentario, lo heterogéneo, la eclosión de mónadas dispersas -en pocas palabras, lo que anunció Popper-, llevó a la renuncia del "esfuerzo del concepto", para decirlo con Hegel, al esfuerzo de encontrar los nexos entre los fenómenos, sus interrelaciones. Por eso este volcamiento implica una "supresión del pensamiento".

Desde luego, esa renuncia al esfuerzo del concepto está relacionada con el fin de los metarrelatos anunciado por Lyotard. También por la crisis del sistema en filosofía que antes que Nietzsche ya había atacado el acongojado Kierkegaard cuando decía claramente atacando a Hegel que él no era un filósofo y que "no escribe sistemas, ni promesas de sistemas". Por lo demás, el danés comprendía muy bien el proceso de secularización de la sociedad que, en últimas, llevó a la debacle de los metarrelatos. Eso es claro cuando afirma que vive en "una época en que la pasión se borra de un trazo para beneficio de la ciencia" (2008: 10). Y esa secularización que llevó al nihilismo y que se acentuó después de la posguerra no sólo llevó al descrédito los metarrelatos y las utopías, sino también al derribe del papel fundante del pensamiento, de la filosofía, es decir, atacó la "filosofía primera" en nombre del pluralismo cultural del mundo, de las variadas cosmovisiones, del relativismo y la diversidad epistémica que desembocó en la interdisciplinariedad. Y así se llegó a lo que Gianni Vattimo ha llamado sugestivamente: "la secularización de la filosofía" (1991: 37-53). Si antes la secularización significaba sociológicamente la ausencia de la religión en la sociedad, su no injerencia 
en las instituciones sociales, la educación, la vida política, con Vattimo la "secularización" en la filosofía destierra la "filosofía primera" del pensamiento pues precisamente el mundo se encuentra en una edad "posmetafísica" que hace imposible una explicación unitaria de la realidad. Y es, precisamente, ese rechazo al intento de explicar la realidad ${ }^{7}$, de captar los nexos entre los fenómenos lo que lleva a la afirmación de "lo dado".

Son los motivos anteriores los que están en la base de las alusiones críticas de Gutiérrez al posmodernismo, si bien, como ya he puesto de presente, no hay mención directa ni detenida a la mayoría de los autores posmodernos que he citado en este ensayo. En su obra se alude a ellos genéricamente, y sólo nombra a unos pocos: Derrida, Lyotard, Lacan, Bachelard, de quienes no cita ninguno de sus libros. Este no es el tratamiento que da a Foucault, como veremos más adelante.

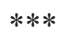

En su libro El arte de la vida Zygmunt Bauman sostiene: "Nuestra época es la de la resurrección de Nietzsche" (2009a: 146). Pues bien, ¿qué pensaba Gutiérrez Girardot sobre esa euforia actual por Nietzsche? ${ }^{8}$, veamos.

$7 \quad$ Al final de la Carta sobre el humanismo Heidegger sostiene: "Lo que hace falta en la miseria universal de ahora: menos filosofía, pero más atención al pensar [...]. El pensar futuro ya no es filosofía, porque piensa más original, que la metafísica, nombre, que dice lo mismo" (1997: 329). Esta es otra muerte más de la filosofía -en el sentido en que Heidegger la equipara con la metafísica-, por eso muchos en la época hablaron sobre el fin de la filosofía. Con todo, cabe la pregunta: ¿no se mantuvo Heidegger en una filosofía primera?

8 Una lectura de Nietzsche, que tal vez muchos puedan considerar conservadora, pero que a mi juicio, nos previene contra los excesos de las interpretaciones posmodernas, se encuentra en el libro Aprender a vivir de Luc Ferry (2007: 181-
En Nietzsche y la filología clásica Gutiérrez Girardot se refiera al libro Nietzsche y la filosofia de Deleuze de 1962 afirmando que "el texto es un pretexto para posmodernizar a Nietzsche y referirlo, involuntariamente, a espectáculos: Lacancan y Derridada" (2002: 198). El libro de Gutiérrez es un estudio clásico sobre la relación de Nietzsche con la filología de su época, de su crítica a esa filología y esclarece muy bien los antecedentes de El nacimiento de la tragedia (1872). Ese libro se publicó en Argentina en 1966 y se reeditó en Colombia. Es una buena pieza que muestra al Gutiérrez filósofo y filólogo. Para Gutiérrez, los posmodernos no entendieron la "lucha cuerpo a cuerpo con la filología clásica" que hizo Nietzsche. Ellos "que nombran a Nietzsche precursor o pontífice de la posmodernidad", y que se beneficiaron de su crítica y de la de Heidegger a la filosofía occidental, lo rebajaron a "ídolo de sus convulsivas y pretenciosas insuficiencias", obviando, "como tantas advertencias semejantes", que Nietzsche no quería ídolos como él mismo lo dice en Ecce Homo.

El descuerdo de Gutiérrez frente a la posmodernización de Nietzsche lo podemos comprender mejor si tenemos presente que el alemán dice en Homero y la filología clásica (1869):

Con ello ha de manifestarse que
toda y cualquier actividad filológica
debe estar cercada y vallada por una
visión filosófica del mundo en la que
todo lo singular y lo aislado se eva-
pore y sólo se mantenga la totalidad
y lo unitario (Nietzsche, 2002: 222).

Esta cita de Nietzsche es fundamental para entender el malestar de Gutiérrez por el tratamiento posmoderno del filósofo alemán.

240). Igualmente, la interpretación que Zygmunt Bauman realiza en El arte de la vida (2009a). 
Aclarando que Gutiérrez es consciente de que Nietzsche "se sustrae a toda captación lógica y a toda comprensión unificadora" y anotando, además, que el colombiano deja de lado al viejo Nietzsche. ¿Por qué es importante la crítica de Nietzsche a la filología clásica? ¿Por qué los posmodernos obvian esta crítica? La respuesta es sencilla, Nietzsche no renuncia a una "visión filosófica del mundo en la que todo lo singular y lo aislado se evapore y sólo se mantenga la totalidad y lo unitario". Nietzsche habla de una visión integradora del mundo que debe construir la filología clásica, habla de lo aislado, de mantener la "totalidad y lo unitario". Esto mismo expresó Gutiérrez al citar una carta de Nietzsche de 1867: "Pues no vamos a negar que a la mayoría de los filólogos les falta aquella sublime visión total de la Antigüedad, porque se colocan demasiado cerca del cuadro e investigan una mancha de aceite en vez de admirar-y lo que es más-de gozar los grandes y audaces rasgos de todo el cuadro" (citado en Gutiérrez, 1998: 61). De nuevo Nietzsche hablando de "visión total de la Antigüedad", criticando la miopía especialista, llamando a tener una visión de "todo el cuadro", esto es, "una visión filosófica del mundo", completa, compleja.

Es claro que ese Nietzsche, el de la crítica a la filología clásica, le hubiera hecho rasgar las vestiduras a todos aquellos posmodernos que renunciaban al "esfuerzo del concepto", al intento de una explicación integradora de los fenómenos sociales; a quienes habían rechazado la historia total y el sentido, es decir, a un Foucault, por ejemplo. Por eso Gutiérrez en otro libro se refiere a La arqueología del saber como una obra de "estirpe aparentemente nietzscheana" (1976: 291). "Aparentemente" porque para Gutiérrez eso no es Nietzsche o, mejor, es antinietzscheano. Y habría que agregar que hoy, tras la aparición del último curso que Foucault dio en Francia en 1984, titulado "El coraje de la verdad", en el cual profundiza su tercera etapa, la de los "mo- dos de subjetivación", que de acuerdo con Gilles Deleuze, no es un "retorno al sujeto" (2006: 170), Gutiérrez podría confirmar que Foucault es "aparentemente" nietzscheano, pues de acuerdo con Fredéric Gross, gran conocedor de la obra de Foucault y editor del mencionado curso, "al retornar con Sócrates a las raíces mismas de la filosofía, Foucault decide inscribir en ella la totalidad de su obra crítica" (2010: 351) ${ }^{9}$. Es decir, Foucault sería aparentemente nietzscheano pues al final de su vida apoyó su filosofía en Sócrates, el primer enemigo de Nietzsche, el corruptor de la juventud antigua, el destructor de la vitalidad griega.

Una vez atados muchos cabos en las sugerencias de Gutiérrez sobre la posmodernidad -lazos que he armado y cuyo sentido comparto en gran parte, y con cierta complicidad-, centrémonos en la crítica que el polemista colombiano hizo a Foucault en un ensayo

9 Aunque en realidad, a favor de Foucault, hay que aclarar aquí que la última etapa, aquella donde hay que hacer de la vida una obra de arte es, realmente nietzscheana. Incluso en ella hay cierto vitalismo en Foucault, al decir de Deleuze. El problema de la autocreación es una herencia de Nietzsche a los posmodernos como bien lo ha señalado Alex Callinicos. Pero en realidad, la estetización de la vida, de la existencia, es un postulado formulado por Friedrich Schlegel, expuesto en el contexto de la Alemania grecofílica de finales del siglo XVIII y comienzos del siglo XIX. Hay que decir, además, que esa propuesta de la vida como una "obra de arte" es una utopía deseable, atractiva, pero parece hecha para ciertos ciudadanos de primera, pues ¿a quién se le ocurriría decirle a un inmigrante rumano, árabe, chino, turco,o a los llamados afro, indigenas desplazados en las grandes ciudades de América Latina, que hagan de su vida, de su existencia, una obra de arte? Esto quiere decir que un cambio en el futuro debe incluir necesariamente una distribución de la riqueza, su desconcentración. Esa es la razón por la cual no se puede descuidar el factor económico, al cual, desde luego, no se reducen las demandas sociales actuales. 
intitulado: "Michel Foucault: los laberintos del estructuralismo" publicado en 1975.

Se podría comenzar preguntando: ¿por qué "los laberintos del estructuralismo" si Foucault dijo en innumerables ocasiones que él no era estructuralista? No hay que olvidar que el libro sobre el cual se centra la crítica es La arqueología del saber de 1969, época para la cual Foucault ya ha publicado Historia de la locura en la época clásica (1961), El nacimiento de la clínica (1963), Las palabras y las cosas (1966), entre sus obras más importantes. Es decir, según lo ha expuesto Deleuze, es la etapa donde Foucault se interesa por el saber, los enunciados, etc., pues su tránsito y su interés hacia el poder se dan con Vigilar y castigar (1975). Dice Deleuze -y téngase en cuenta lo dicho arriba entre la relación de Mayo del 68 con la filosofía posmoderna-: "el 68 puso al descubierto todas las relaciones de poder allí donde se ejercían, es decir, en todas partes. Hasta entonces Foucault había analizado las formas, mientras que ahora pasa a ocuparse de las relaciones de fuerza que subyacen a esas formas. Da un salto hacia lo informe, hacia un elemento que él mismo llama microfísico" (2006: 169). Si nos atenemos a esto, comprendemos que la crítica de Gutiérrez abarca la primera etapa. Y fue, precisamente, en esa etapa donde se ha mostrado más la cercanía de Foucault con el estructuralismo. En el ensayo, dice Gutiérrez, que "Michel Foucault abandonó el frente del variado estructuralismo francés, al que ciertamente, sólo había pertenecido muy casual y marginalmente" (1976: 291), sin embargo, líneas más abajo sostiene que "pese a la novedad de su terminología", ésta es la del estructuralismo. Tal vez la crítica tenga fundamento si miramos que, por ejemplo, en 1966, tras aparecer Las palabras y las cosas, Foucault sostiene en una entrevista:

...los descubrimientos de LeviStrauss, de Lacan, de Dumézil, pertenecen a eso que se ha dado en llamar ciencias humanas pero lo verdaderamente característico es que todas esas búsquedas borran no sólo la imagen tradicional que se tenía del hombre, sino que, a mi juicio, tiendes todas a convertir en inútil, para la investigación y para el pensamiento, la idea misma del hombre. La herencia más gravosa que hemos recibido del siglo XIX -y de la que ya es hora de desembarazarse- es el humanismo (1991: 34).

En esa época Foucault recibió la herencia de los estructuralistas -Lacan, Levi-Strauss, etc.y en ellos fundamenta su antihumanismo, así como la crítica a las ciencias humanas. Frente a esto, lo que afirma Gutiérrez es la cercanía de Foucault a ese estructuralismo, pero no lo vincula directamente a ese movimiento, sin embargo sostiene que mantiene su vocabulario o que sus categorías son las del "estructuralismo".

Lo otro que definitivamente molestó al filósofo colombiano es la crítica al humanismo que planteó Foucault; la posición según la cual el humanismo es un conjunto de buenos deseos, mistificaciones, que moralmente quieren salvar al hombre y que Foucault, como Althusser, denunciaban en la época (1991: 35). Dice Foucault: "Lo que me irrita del humanismo es que es además el parapeto tras el que se refugia el pensamiento más reaccionario, el espacio en el que se asientan alianzas monstruosas" (1991: 36). Esa crítica al humanismo no la compartió Gutiérrez, no porque fuera marxista -ya que no lo fue-, sino porque, entre otras cosas, Foucault parece decir que las monstruosidades del siglo XX se han cometido con la complicidad del humanismo, es decir, y esto es algo que cabría para muchos críticos del humanismo, en esa época asociaron fascismo, nazismo, estalinismo, con esas reivindicaciones por el hombre que han 
existido desde la Antigüedad. El argumento sería más o menos: el humanismo mató al hombre, lo cual parece una simplificación del concepto de humanismo y, correlativamente, una paradoja. Aclarando, además, que ese rechazo, esa "muerte del hombre", parece estar basada únicamente en la experiencia soviética y en la tergiversación que en la URSS hicieron de Marx, tergiversaciones que mostró detalladamente Herbert Marcuse -víctima y duro crítico de los fascismos- en su libro El marxismo soviético (1958); Marcuse, que valga decir de paso, influyó tanto en el movimiento estudiantil de la época en Estados Unidos y desde luego, en Mayo del 68. Es decir, y es algo que comparto, la tergiversación, mutilación y uso ideológico de las teorías de Marx en Rusia, le sirvieron de apoyo a la crítica francesa al humanismo -también debido a Heidegger de donde los franceses tienen sus primeras inspiraciones, y gracias a la pregunta de Jean Baufret que da origen a la Carta sobre el humanismo y cuyos ecos encontramos hoy en el "indefinible" Peter Sloterdijk-. A fortalecer esa crítica del humanismo contribuyó el justo rechazo a la política soviética, a su violencia, a su degradación del hombre, que, entre otras cosas, Albert Camus denunciaba con ahínco años antes de la llamada Revolución cultural de los años sesenta y que encontramos, por ejemplo, en su famoso libro El hombre rebelde (1951).

Todos los motivos anteriores se encuentran en la base del "antihumanismo" francés, lo cual sólo se entiende, especialmente en estos países, con una detenida historia intelectual de la época, labor difícil en un tiempo donde la modorra mental conspira precisamente contra el seguimiento de los procesos históricos, y donde reina el desinterés por el pasado, lo viejo o la tradición.

Y es en este rechazo al pasado donde Rafael Gutiérrez Girardot ubica los motivos de obra de Foucault, y de los posmodernos en general, como ya ilustramos con anterioridad:

La discontinuidad consiste en la negación de la continuidad, en qué consiste la historia, y del sentido, en qué consiste la filosofía, es una expresión de una actitud de posguerra: comencemos de nuevo, ignoremos el pasado. El mundo comienza con nosotros (Gutiérrez, 1976: 294).

Y agrega que el libro de Foucault, que Gutiérrez leyó en versión francesa, "es de 1969, un año después del 68 parisiense, que reclamaba con justicia la inversión de todos valores. El libro de Foucault recoge y refleja esa ruptura" (1976: 294). Pero lo grave de que "el mundo comienza con nosotros" es, para el colombiano, que lo mismo sucede para ellos con la filosofía: ésta comienza con nosotros. A eso se debe el "aventurerismo teórico", el arbitrismo, y el hecho de que los posmodernos quieran llenar los presuntos "déficit de teoría" con "inflamaciones terminológicas" o con las "grandes revoluciones verbales". Es decir, a eso se debe la exuberancia verbal de los posmodernos. De ahí proviene también el hecho de que Foucault pretenda mostrar como nuevo lo que en realidad ya es viejo, lo que en realidad ya se ha tratado en la filosofía tradicional que él, y otros posmodernos, quieren destruir. Eso es lo que pasa, por ejemplo, con el concepto de "campo discursivo".

Foucault define cómo debe ser el análisis del "campo discursivo":

...se trata de asir el enunciado en la estrechez y la singularidad de su acontecimiento, de determinar las condiciones de su existencia, de fijar más justamente los límites de ésta, de establecer sus correlaciones de otros enunciados que pueden ser ligados a 
aquél, de mostrar qué otras formas de enunciación excluye [...]. Se trata de mostrar por qué no puede ser diferente de lo que era, en que es exclusivo frente a los demás, cómo ocupa en medios de otros y por relación con otros un puesto que ningún otro podría ocupar (Foucault, citado en Gutiérrez, 1976: 292).

Frente a este concepto de La arqueología del saber, el crítico colombiano sostiene que "sorprende que lo que considera como nuevo análisis no es en realidad otra cosa que la descripción de un principio fundamental de la filosofía especulativa y sistemática del siglo pasado, un principio además que es el de la continuidad que [Foucault] pretende destruir" (1976: 292). Es decir, para el colombiano, lo que contiene esa descripción ya estaba en Hegel, en Fichte, Schelling, y en ellos eso era la "demostración de la necesidad de todo enunciado": "llegar a enunciados que no pueden ser diferentes de lo que eran, que ocupan un puesto que no puede ocupar ningún otro. El nuevo análisis, pues, es muy viejo". Ahora, aquí se trata también de la continuidad, pues ¿qué quiere decir, por ejemplo, relacionar un enunciado con otro, de fijar los límites de la existencia de un enunciado?, ¿qué es esto, sino continuidad? Lo mismo cabe decir, por otro lado, del análisis que Foucault hace de los discursos, su relación con otros, la determinación de lo que pueden o no pueden decir, de cómo se conservan y se reproducen, "su correlación con otros sucesos anteriores o simultáneos, discursivos o no" (Foucault, 1991: 57).

Es este análisis el que lleva a Gutiérrez a afirmar:

Foucault se ve obligado a definir la discontinuidad y lo Otro en general con el lenguaje del sentido y de la continuidad. No resulta por eso sorprendente que él hable de un "sistema de dispersión" [...] lo Otro se ha vuelto, de nuevo, sistema, una nueva continuidad (1976: 295).

Pero en realidad, concluye Gutiérrez, esa "novedad es verbal e impracticable" a pesar de que las teorías de Foucault puedan

...fascinar y sin duda han fascinado", además de que resulta "paradójico que quien niega la unidad en qué consiste un libro, se esfuerce en escribir un libro, publicarlo, darle sentido, situarlo en el marco genérico del ensayo (no cita sus fuentes) para demostrar la insensatez de eso que lo otros llaman libro [...] demostrando con ello su propia insensatez. También niega la "obra", aunque no dejan de ser frecuentes en el libro las vanidosas referencias autointerpretativas a su propia obra (1976: 295).

Son todos esos problemas los que Gutiérrez refiere como "los laberintos del estructuralismo". Personalmente creo que si bien la filosofía consiste en crear conceptos como sostienen Deleuze y Guatari -cuando esto es realmente necesario-, la filosofía francesa parece abusar de tal principio, cayendo en una buena cantidad de contradicciones, de laberintos. Sabemos que la obra de Deleuze está llena de metáforas, por ejemplo, los conceptos de rizoma, máquinas de guerra, aparatos de captura, máquinas deseantes, etc., sin embargo, él sostiene que las metáforas son inútiles y fastidiosas (Deleuze, 2006: 49). Otras afirmaciones son realmente sorprendentes: "la filosofía no es comunicativa, ni tampoco contemplativa o reflexiva" (1976: 217). Resulta curioso además que diga: "Para mí el constructivismo sustituye la reflexión y lo que sustituye a la comunicación es una especie de expresionismo" (1976: 234). De 
tal manera que la filosofía no es discusión, reflexión, ni comunicación, sino más bien, constructivismo y expresionismo, esto es, tiene las características de dos de los movimientos de la vanguardia donde, en el caso del constructivismo ruso de Vladimir Tatlin, la obra de arte es un conjunto de agregados de piezas metálicas o elementos de uso cotidiano: uno sobre otro o al menos un collage. ¿Son eso - sin que se les reste su valor y sus aportes $^{10}$ - los libros de Deleuze y Guatari? Aquí estamos ante el deseo consciente de innovar, de transgredir, de chocar la tradición. En fin, algo muy Mayo del 68. Por lo demás, innovar no está mal, es necesario para terminar con la esclerosis y el anquilosamiento, pero cuando se excede en las arandelas, en el afán de impresionar, deslumbrar y desconcertar, el resultado parece impostado. Es este mismo ánimo el que lleva, por ejemplo, a Jean-Luc Nancy a proponer una "democracia sin principios", como si el atrevimiento tuviera alguna vez una posibilidad de ser plasmado en una constitución política de algún Estado (2009) o la llamada "comunidad"11 sin lazos, conformada por individuos sin nexos,

10 Por ejemplo, la descripción del modus operandi del capitalismo de las últimas décadas y su relación con el "sujeto", la teoría de la "sociedad de control" que tanto ha influido, por ejemplo, en Antonio Negri y Michael Hardt. Si bien el pensamiento de Deleuze es enrevesado, no podría tildarse de cómplice del capitalismo.

11 También llama la atención en la actualidad la vuelta a temas que se creían superados. El de la comunidad es uno de ellos. De éste se han ocupado Nancy y Agamben, entre otros. Lo mismo sucede con el tema de la teología política, la secularización y más recientemente, con el problema de la ideología, este último retomado por Zygmunt Bauman en su libro En busca de la política (2009b: 119-139) y por Slavoj Zizek en El espectro de la ideología. (Mejía, 2009: 383 y ss.). Cabría la irónica pregunta: ¿están resucitando los muertos a quienes Lyotard, Fukuyama y otros apresuradamente les habían dado el certificado de defunción? sin identidades, de la que se ha ocupado el italiano Giorgio Agamben, influenciado y en diálogo con los franceses -y cuya obra tiene el mérito de poner de presente, complementando a Foucault, que la biopolítica viene desde la Antigüedad-(2006: 69-71). Es todo esto lo que se ha llamado "los trapecismos verbales, los juegos de palabras que nos lanzan en un escarceo puramente retórico" (Botero, 2001: 131) o la "demagogia teórica" y "cierta voluntad muy francesa de originalidad", como sostuvo en su época Estanislao Zuleta (2004: 274).

Volviendo al tema de Gutiérrez y Foucault, en una entrevista con Numas Armando Gil, el filósofo colombiano, de forma excesiva, sostuvo que Foucault era como un Ortega y Gasset, lo que francamente me parece desacertado, sobre todo si tenemos en cuenta que sobre Ortega Gutiérrez dijo que era un simulador, estafador, torero, conejo, que se saltaba y capoteaba toda la tradición filosófica, y que quería ponerse en el pináculo de la filosofía moderna, tal como ya lo he expuesto detalladamente en el libro La concepción de Hispanoamérica en Rafael Gutiérrez Girar$\operatorname{dot}$ (2010a: 71 y ss.). A juzgar por las obras de Ortega y Foucault, cabría decir que el español careció del rigor del francés y que el francés careció del "genio destellante" del español. Por lo demás, tal vez su único puente es la irreverencia y en parte el estilo, en el cual Ortega fue un maestro de la retórica.

Para finalizar esta segunda parte, Gutiérrez en los años posteriores no cambió su valoración sobre Foucault. En un artículo póstumo, publicado en el 2008, titulado "Problemas de la filosofía en Colombia", sostuvo: "E1 ecléctico Foucault, que puede considerarse como medio representante a medias del estructuralismo francés y de la filosofía analítica inglesa, por ejemplo, "elabora" una teoría del documento, que no sólo ya se encontraba en la Historik de Droysen (de 
1862 a 1879), sino que además se hallaba allí mejor formulada que en Foucault. El mismo Foucault, asegura en su Historia de la sexualidad, de 1976, que hasta ahora no se ha hecho cosa semejante, lo cual sorprende o tiene que sorprender si se tiene en cuenta que ya en 1909 el "coleccionista e historiador" Eduard Fuchs, como lo llama Walter Benjamín, había publicado una muy documentada historia de las costumbres, que en realidad no era otra cosa que una historia de la sexualidad desde el Renacimiento. Cierto es que no todas las tendencias "metodológicas" y "cientificistas" y "estructuralistas" cometen las ligerezas de Foucault. Muchas de ellas, como lo apunta el ya citado Apel, desarrollaron de manera amplia y de modo eficaz los problemas de las "fenomenologías" o, más exactamente, planteados por esa y otras corrientes afines. Pero a todas ellas les es común, especialmente en sus seguidores, no siempre en sus fundadores, la ruptura con la historia propia, que en algunos casos, como en el de Von Wright, vuelve a introducirse en el tratamiento nuevo de algún problema viejo. Esa ruptura con la historia propia resultó favorable a una forma terca del escolasticismo y de los hábitos intelectuales hispánicos: la de orientarse por la última autoridad o por la última de que se tiene noticia en esos países ${ }^{12}$ (2008: 59-70).

12 Este problema señalado por Gutiérrez Girardot, el de que en Hispanoamérica se tiene el hábito de "orientarse por la última autoridad o por la última de que se tiene noticia”, es francamente notorio entre nosotros. Gran parte de los filósofos colombianos adoptan un pensador de Europa o de Norteamérica y asumen sus obras, conceptos, metáforas, imágenes, ideas (y en algunos casos hasta sus poses) y se convierten en los ventrílocuos de ellos. Ya no hablan por sí mismos, sino de su boca sale el vocabulario, los motivos, los temas, de sus ídolos. Se adoptan sin una discusión seria, sin una confrontación de sus teorías con la tradición filosófica. Esto atenta, realmente, contra una buena recepción del pensamiento europeo, lo cual es fundamental, y sólo fomenta la muy denunciada

\section{-III-}

\section{Apreciaciones finales}

Si bien en la obra de Rafael Gutiérrez Girardot no encontramos una crítica detallada a los autores posmodernos, ni una discusión de tú a tú, como solía decir, con una obra de los mismos; así como su crítica a los posmodernos se vale sólo del primer Nietzsche y su crítica a Foucault no abarca parte de la segunda y la última etapa del pensador francés, a pesar, repito, de estas inconsistencias, en su libros encontramos una buena cantidad de referencias, de dardos, cargados de sugerencias que me han permitido en este ensayo reconstruir esa crítica con algún detalle. También ha intervenido en esa "reconstrucción" cierta complicidad y mi afinidad (aunque con las discrepancias con el autor que he expuesto en La concepción de Hispanoamérica en Rafael Gutiérrez Girardot, en el sentido de que si bien no desconozco algunos aportes valiosos del pensamiento posmoderno para el análisis del complejo y caótico mundo actual, tales como su apuesta por la diferencia, la diversidad, el pluralismo, la crítica de las filosofías de la historia, sus aportes para el análisis de los medios de comunicación, cierta sociología de las generaciones actuales, no comparto en términos generales su crítica de la utopía, la manera como termina haciéndole juego al capitalismo al renunciar a una explicación integral, a una visión total "del cuadro" (Nietzsche) donde se relacionen todos los fenómenos, los hechos, los discursos, las prácticas, las mentalidades y se los conecten con los múltiples contextos que los hacen posibles y los producen. Es decir, para decirlo con Deleuze, mientras no se conecte lo molecular con lo molar, la microfísica del poder con la macrofísica. No se trata de que esa explicación integral del cuadro,

subalternidad mental. Eso es lo que sucede cuando se asimila la crítica con la adulación. 
su comprensión, absorba a esos fenómenos dictatorialmente y los remita a una "filosofía primera" o a una teoría general o a una sola cosmovisión hermética del mundo; se trata, más bien, de abogar por una construcción paciente, detenida, rigurosa, que alumbre un horizonte que nos permita seguir en la búsqueda de un mundo mejor. Es decir, rechazo el "posmodernismo celebratorio" del que habla Boaventura de Sousa Santos (2009: 339-365) y la apuesta por una transformación radical de nuestra vida actual, lo que requiere tener en cuenta los nuevos movimientos, actores y demandas sociales -feminismo, ecologistas, ambientalistas, movimientos antirracistas, etc.-, cuyas peticiones no se reducen a reivindicaciones económicas.

Tampoco comparto la crítica al humanismo, como se esbozó en la segunda parte. ¿Por qué?, porque cuando los posmodernos rechazan el humanismo evidencian una clara miopía: desconocen que no ha habido un solo humanismo, lo cual puso de presente el mismo Heidegger en la Carta sobre el humanismo ${ }^{13}$; que éste corresponde a cada época histórica donde se reivindica un tipo determinado de hombre y que no siempre ha sido un engendro macabro que no ha aportado nada positivo a la humanización del hombre -así cada día aparezca una nueva barbarie-. Esa crítica tiene el mismo defecto de esa manera de negar (valorar) los avances de las reformas penales del siglo XVIII, como si fuera mejor que el rey decrete por voluntad la muerte de alguien a quien se le juzga por

13 En la Carta sobre el humanismo Heidegger sostiene: "Todo humanismo está basado en una metafísica, o el mismo se hace fundamento de una. Toda determinación de la esencia del hombre, que ya presupone la interpretación de los existente sin la pregunta por la verdad del ser, sea con saber, sea sin saber, es metafísica" (1997: 294). Según esto, para Heidegger el humanismo es un "metarrelato", tal como se interpretará después. un delito prescrito legalmente. Por lo demás, mientras haya historia, esto es, mientras exista el hombre que la hace y la padece, ya que éste es el único que tiene "conciencia de vida", será deseable pensar el tipo de humano que con su ciencia, sus saberes, sus modos de vida y todas las transformaciones, que a la vez lo autotransforman, habitará el desconocido futuro. De tal manera que hablar de un poshumanismo como lo hace el erudito y muy actual Peter Sloterdijk en Reglas para el parque humano (1999) es por ahora sólo una propuesta más del gran mercado de ideas -buenas y malas-circulantes, a menos que el hombre -o lo que quede de él, de su "esencia" y "dignidad"- perezca definitivamente y este mundo pase a ser gobernado por robots u otras inteligencias, es decir, cuando ya no quede ni un vestigio de eso que alguna vez se llamó "ser humano" y gracias a su inexistencia no necesite ninguna reivindicación. Sin embargo, mientras haya destrucción de la vida biológica, empobrecimiento de la vida material y espiritual, problemas que tienden a acentuarse en un mundo que ha hecho de la "multiplicación de la cantidad por la cantidad su afán infinito”, es decir, la multiplicación del sinsentido, ¿por qué rendirse ante lo real tal como es?, ¿por qué no encarnar las ideas en prácticas que desde adentro desborden, resistan y redireccionen el mundo existente, ideas que hay que crear y someter al devenir y a las circunstancias, ideas que emerjan desde el corazón de la necesidad histórica particular que nos atañe? En fin, ¿por qué no desear evitar la "muerte del hombre", su extinción?

Asimismo, no comparto la crítica al intelectual. Aquí, como en otros casos señalados, el asunto es un juego de palabras, pues los posmodernos critican al intelectual tomando como referente al intelectual marxista -lo mismo que en su crítica al humanismo-, es decir, aquél que desde afuera hacía entrar 
en conciencia al proletariado o pretendía representarlos o formar una visión única y definitiva del mundo. Pero es que el intelectual en la historia ha sido algo más que eso, ha luchado contra la injusticia, el poder, el racismo y lo ha hecho desde adentro, de manera franca, sincera, con coraje, arriesgando la vida, esto es, ha hecho lo que Foucault, su crítico, expone en sus últimas lecciones publicadas con el título "El coraje de la verdad" al referir la parrhesía de los cínicos (2010: $243 \mathrm{ss}$ ), o, sino, ¿qué fue lo que hicieron Anatole France, Emil Zola y Marcel Proust en el "Manifiesto de los intelectuales" frente al caso Dreyfuss en 1898, justamente cuando la categoría de "intelectual" surge para la sociología del saber?

Por otro lado, es posible que alguien que lea la crítica de la posmodernidad planteada aquí sostenga que quien escribe no entiende el mundo actual, que vive añorando una revolución que nunca fue; que no comprende el "plano de la inmanencia" y la destradicionalización de las sociedades actuales, o las transformaciones que las comunicaciones, el consumismo, etc., han producido; que no reconozca los aportes de Foucault - a quien valoro altamente ${ }^{14}-\mathrm{o}$, en el peor de los casos,

14 Hoy una comprensión de la modernidad y el problema del Estado no se comprende cabalmente sin el aporte que hizo Foucault de la "gubernamentalidad”, así como no se comprende sin los análisis de Marx, Max Weber, parte de la obra de Lukács y la Escuela de Frankfurt. Así sean notorias las diferencias entre ellos. Por lo demás, lo más valioso de la obra de Foucault- a mi juicio- está en los aportes de la primera y la segunda etapa (la del saber y la del poder), pues la tercera es la reivindicación de lo que hoy se llama "vida filosófica", lo cual era un haber común de la antigüedad, haber que él mismo ha ayudado a mostrar junto con otros como Pierre Hadot y Michel Onfray. Esa vida está somatizada, por así decirlo, en Epicuro, sugerida en Séneca, y en el siglo XX en María Zambrano, para sólo mencionar algunos ejemplos. De esa que me tilden de marxista ortodoxo, mesiánico e ingenuo, obviando y desconociendo que ni siquiera soy marxista, pero que no desconozco esos aportes. En realidad, no se trata de una incomprensión. Lo que está de fondo es la posibilidad de seguir reivindicando el humanismo -así el ismo les moleste-, la utopía, la crítica, el papel del intelectual; reivindicar la necesidad de una articulación de los movimientos sociales, las filosofías, las ciencias humanas en general, para transformar consciente y solidariamente el mundo que habitamos, partiendo del trabajo microtópico, en una lucha día a día, sin esquemas a priori. Eso es así porque la dispersión no lleva a nada. Se trata de no claudicar ante la historia sacrificial, ni de rendirse ante la catástrofe, con el fin de buscar un mundo donde sea posible lo que he llamado una "forma-vida-orgánica", esbozada apenas en el ensayo "Crítica y redefinición de la categoría de progreso" (Pachón, 2010b: 131154). Se confiesa esto con coraje, sinceridad y franqueza y recordando con Nietzsche que hay que evitar el mal gusto de querer estar de acuerdo con un gran número de gentes, esto es, con aquellos que no comprenden que la inconformidad con la realidad que se tiene parece pertenecer inevitablemente al hombre que la habita, sobre todo en momentos extremos o de crisis.

Para concluir es necesario decir que un intelectual bien formado como Gutiérrez en filosofía, derecho, sociología, crítica literaria; conocedor de la literatura hispanoamericana, desde la Patagonia hasta España; conocedor de la filosofía, la literatura alemanas; conocedor en fin, de la historia y de los procesos de la "era del capital" o de la "unificación del mundo", rechaza el posmodernismo, entre otras cosas, porque creía en la utopía de Bolívar y Martí y el papel que el intelectual

tercera etapa se resalta el papel político que da Foucault al cuidado de sí y a la parrhesía (2010). 
tenía en ese "proyecto". Gutiérrez creyó y reivindicó la dignidad de América. Por lo demás, la posmodernidad para él no era nada nuevo, pues la "modernidad es, esencialmente, la variación histórica, contradictoria y polémica de la concepción ilustrada de la crítica" (2004: 207). Y hay que decirlo: hoy nadie ha renunciado a la libertad y a la igualdad, ni tampoco a la crítica-todos estos principios son parte del proyecto moderno, aunque hoy se entiendan de manera distinta-, pues la llamada posmodernidad ha sido también eso: una "autocrítica" de la modernidad, tal como lo ha sostenido el propio Santiago Castro-Gómez en su libro Crítica de la razón latinoamericana (1996).

Hoy, cuando las guerras abundan, cuando el deseo de libertad e igualdad no cesan, el hombre sigue buscando tener una mejor vida y una mejor relación con su medio y sus congéneres; cuando el hambre y la pobreza cunden y el planeta parece marchar hacia un "desierto superpoblado" como decía Ernesto Sábato; hoy, precisamente, cuando el mundo es más complejo, más caótico, -más "transparente" en el sentido de Vattimo- Como sostiene un gran sociólogo de nuestra época:

... nunca antes había sido tan fuerte ni se había sentido de forma tan dolorosa la necesidad de puntos de orientación y guías de ayuda. Sin embargo, nunca antes había habido tan pocos puntos de orientación firmes y fiables y guías fidedignas (al menos con el volumen y la intensidad de la necesidad) (Bauman, 2009a: 107).

Creo que construir esos puntos, esas guías, es la responsabilidad de las generaciones actuales.

\section{Referencias}

Adorno, T. y Horkheimer, M. (2009). Dialéctica de la Ilustración. Madrid: Editorial Trotta.

Agamben, G. (2006). La comunidad que viene. Valencia: Editorial Pre-textos.

Aguirre, C. (2010). La historiografia en el siglo XX. Bogotá: Ediciones desde Abajo.

Bauman, Z. (2009). El arte de la vida. De la vida como obra de arte. Barcelona: Ediciones Paidós.

Bauman, Z. (2009a). En busca de la política. México: Fondo de Cultura Económica.

Botero, D. (2001). El poder de la filosofía y la filosofia del poder (3 $3^{\text {a }}$ ed., t. II). Bogotá: Universidad Nacional de Colombia.

Callinicos, A. (1998). Contra el postmodernismo. Una crítica marxista. Bogotá: El Áncora Editores.

Deleuze, G. (2006). Conversaciones. Valencia: Editorial Pre-textos.

Ferry, L. (2007). Aprender a vivir. México: Editorial Taurus.

Foucault, M. (1991). Saber y verdad. Madrid: Ediciones de La Piqueta.

Foucault, M. (2008). Nacimiento de la biopolítica. México: Fondo de Cultura Económica.

Foucault, M. (2008). Un diálogo sobre el poder y otras conversaciones. Madrid: Alianza Editorial.

Foucault, M. (2010). El coraje de la verdad. México: Fondo de Cultura Económica.

Fukuyama, F. (1992). El fin de la historia y el último hombre. Bogotá: Editorial Planeta. 
Gutiérrez, R. (1968). El fin de la filosofía y otros ensayos (vol. II). Medellín: Ediciones Papel Sobrante.

Gutiérrez, R. (1976). Michel Foucault: los laberintos del estructuralismo. En Horas de estudio. Bogotá: Instituto Colombiano de Cultura.

Gutiérrez, R. (1989). Hispanoamérica: imágenes y perspectivas. Bogotá: Editorial Temis.

Gutiérrez, R. (1998). Insistencias. Bogotá: Editorial Ariel.

Gutiérrez, R. (2001). El intelectual y la historia. Caracas: Fondo Editorial La Nave Va.

Gutiérrez, R. (2002). Nietzsche y la filología clásica. La poesía de Nietzsche. Bogotá: Editorial Panamericana.

Gutiérrez, R. (2004). Heterodoxias. Bogotá: Editorial Taurus.

Gutiérrez, R. (2008). Problemas de la filosofía en Colombia. Revista Aquelarre, núm. 7.

Gutiérrez, R. (2009). El partido liberal está en crisis permanente. Revista Babel, núm, 11.

Heidegger, M. (1997). Carta sobre el humanismo. Revista Politeia, núm. 21.

Heller, A. (1994). Los movimientos culturales como vehículo de cambio. En Colombia: el despertar de la modernidad. Bogotá: Ediciones Foro Nacional por Colombia.

Hobsbawn, E. (2006). Historia del siglo XX. Barcelona: Editorial Crítica.

Kierkegaard, S. (2008). Temor y temblor. Buenos Aires: Editorial Losada.

Lipovetsky, G. (2002). La era del vacío. Barcelona: Editorial Anagrama.
Lyotard, J. (1994). Respuesta a la pregunta, ¿qué es lo posmoderno? En Colombia: el despertar de la modernidad. Bogotá: Ediciones Foro Nacional por Colombia.

Marcuse, H. (1981). El hombre unidimensional. Barcelona: Editorial Ariel.

Mejía, Ó. (2009). Cultura política, sociedad global y alienación. Bogotá: Universidad Nacional de Colombia.

Nancy, J. (2009). La verdad de la democracia. Buenos Aires: Amorrortu Editores.

Negri, A. (2007). Goodbye Mr. Socialism. La crisis de la izquierda y los nuevos movimientos revolucionarios. Barcelona: Ediciones Paidós.

Nietzsche, F. (2002). Homero y la filología clásica. En Nietzsche y la filología clásica. Bogotá: Panamericana Editorial.

Pachón, D. (2010a). La concepción de Hispanoamérica en Rafael Gutiérrez Girardot. Bogotá: Universidad Santo Tomás.

Pachón, D. (2010b). Crítica y redefinición de la categoría de progreso. Hacia una forma vida orgánica. Revista de Ciencia Política, núm. 9, Bogotá: Universidad Nacional de Colombia.

Popper, K. (1967). La sociedad abierta y sus enemigos (t. II). Buenos Aires: Ediciones Paidós.

Santos, B. (2009). Una epistemología del sur. Buenos Aires: CLACSO - Siglo XXI Editores.

Sloterdijk, P. (1999). Reglas para el parque humano. Una respuesta a la Carta sobre el humanismo. Recuperado de http:// musoniorufo.zip.net/parque-humano.pdf

Tobar, J. (2004). La nueva democracia republicana: la crítica del posestructuralismo 
francés a los supuestos nietzscheanosheideggerianos. En El posestructuralismo en la filosofía política francesa contemporánea. Bogotá: Universidad Nacional de Colombia.

Vattimo, G. (1991). Ética de la interpretación. Barcelona: Ediciones Paidós.

Vega, R. (1997). Postmodernismo y neoliberalismo: la clonación ideológica del capitalismo contemporáneo. Recuperado de http://www.pedagogica.edu.co/storage/folios/articulos/fol07_07art.pdf
Vermeren, P. (1995). La filosofía, el Estado, la revolución. Revista Ideas y Valores, núms. 98-99.

Zambrano, M. (2000). La agonía de Europa. Madrid: Editorial Trotta.

Zambrano, M. (2005). Hacia un saber sobre el alma. Buenos Aires: Editorial Losada.

Zuleta, E. (2004). El pensamiento psicoanalítico. Medellín: Hombre Nuevo Editores. 